\title{
PROTEUS SYNDROME - SEGMENTAL OVERGROWTH WITH MULTIPLE NEVI
}

\author{
P. P. Ramasamy ${ }^{1}$, S. Bharathi², B. Eswaramoorthi' ${ }^{3}$, R. Madhavan ${ }^{4}$, A. N. M. Maalik Babu ${ }^{5}$
}

\section{HOW TO CITE THIS ARTICLE:}

P. P. Ramasamy, S. Bharathi, B. Eswaramoorthi, R. Madhavan, A. N. M. Maalik Babu. "Proteus Syndrome Segmental Overgrowth with Multiple Nevi". Journal of Evolution of Medical and Dental Sciences 2015; Vol. 4, Issue 08, January 26; Page: 1388-1393, DOI: 10.14260/jemds/2015/194

ABSTRACT: Proteus syndrome is a rare hamartomatous disorder characterized by various cutaneous and subcutaneous lesions, including vascular malformations, lipomas, hyperpigmentation, and several types of nevi. Partial gigantism with limb or digital overgrowth is pathognomonic of Proteus syndrome. We report a case of proteus syndrome in a 45 year old man, who presented with hypertrophy of index finger of both hands and middle, ring finger of left hand, verrucous lesions over left axilla and two firm swellings over left palm for the past 15 years. Clinical findings, histopathology and imaging studies fulfilled the criteria of proteus syndrome which is rarely reported in literature.

KEYWORDS: Gigantism, Hamartoma, Epidermal nevi, Proteus syndrome.

INTRODUCTION: Proteus syndrome is a sporadically occurring hamartomatous disorder associated with irregular asymmetric overgrowth of multiple body tissues of various cell lineages. The incidence is 1 in one million people worldwide.

CASE REPORT: A 45 year old man presented with progressively increasing overgrowth of right index finger, left middle and ring fingers and hypertrophy of left forearm, over a period of past 15 years. He had two swellings over left palm and multiple grouped verrucous lesions over left axilla for past 15 years. No history s/o any systemic involvement. No history of similar illness in the family members.

On dermatological examination there was hypertrophy of left forearm with digital overgrowth of index, middle and ring fingers of left hand (Fig. 1). Hypertrophy of right index finger was also noted (Fig.2). Two firm swellings were seen over the left palm (Fig. 2). There was multiple grouped hyperpigmented verrucous papules and plaques seen over the left axilla (Fig. 3). A linear hyperpigmented lesion studded with few verrucous papules following Blaschko lines was also noted over left shoulder and arm (Fig. 4). Peripheral pulses were normally felt.

The clinical Differential diagnosis like Proteus syndrome, Klippel-Trenaunay syndrome, Epidermal nevus syndrome and other vascular malformations were considered and the relevant investigations were carried out. Biopsy was taken from both the axillary lesion and palmar lesion. The histopathology of verrucous axillary lesion showed epidermal hyperkeratosis, acanthosis and papillomatosis which was consistent with epidermal nevi (Fig. 5). The histopathology of palmar lesion showed hypercollagen which was suggestive of connective tissue nevi (Fig.6). On special stains with Masson trichrome and Verhoeff -van Gieson connective tissue nevi was confirmed (Fig. 7) \& (Fig. 8)

Radiographs of both hands revealed asymmetric macrodactyly, hyperostosis and over growth of soft tissue in left index, middle and ring fingers and also in index finger of right hand (Fig. 9).On CT angiogram of left upper limb, extensive low flow vascular malformation which consisted of enlarged veins in subcutaneous, muscular and inter muscular planes of left forearm was observed (Fig. 10). Carpal tunnel and extensor compartment of left hand were also involved. 
Arterial system was normal except for mild prominence in ulnar, radial and interosseous arteries (Fig.11). Liver and renal function tests were normal. Chest and skull X-ray were normal. Based on clinical, histopathological and radiolgical findings we arrived at the final diagnosis of Proteus syndrome.

DISCUSSION: Proteus syndrome is a rare, sporadic disease with patchy or mosaic manifestations. Cohen and Hayden identified the syndrome first in 1979.[1] Later in 1983, Wiedermann named it as "Proteus syndrome" after the Greek god Proteus, who could change his shape at will to avoid capture. The name reflects the highly variable manifestation of this disorder.[2] In 2011, Lindhurst et al published a paper regarding the mutation in AKT1 as the cause of proteus syndrome.[3] Male to female ratio is 1.9:1[4]. Symptoms usually progress until puberty, when there seems to be a plateau.[5]

Diagnosis of Proteus Syndrome was based on criteria provided by Biesecker et al.[6] (Table - 1). In our case all the general criteria was satisfied along with one from category A, two from category $\mathrm{B}$ and one from category $\mathrm{C}$ of specific criterias.

Table 1: The Biesecker diagnostic criteria for Proteus syndrome.

\begin{tabular}{|c|c|c|c|}
\hline \multicolumn{4}{|c|}{ To make a diagnosis of PS, one must have all the general criteria, and various specific criteria } \\
\hline \multicolumn{2}{|c|}{ General Criteria } & \multicolumn{2}{|c|}{ Specific Criteria } \\
\hline \multicolumn{2}{|c|}{ All the following: } & \multicolumn{2}{|c|}{ Either: $\quad$} \\
\hline \multicolumn{2}{|c|}{ Mosaic distribution of lesions } & \multicolumn{2}{|c|}{ Category A or, } \\
\hline \multicolumn{2}{|c|}{ Sporadic occurrence } & \multicolumn{2}{|c|}{ Two from category B or, } \\
\hline \multicolumn{2}{|c|}{ Progressive course } & \multicolumn{2}{|c|}{ Three from category $\mathrm{C}$} \\
\hline \multicolumn{4}{|c|}{ Specific criteria categories } \\
\hline A. & 1. Cerebriform connective tissue nevus & C. & 1. Dysregulated a dipose tissue \\
\hline \multirow[t]{17}{*}{ B. } & 1. Linear epidermal nevus & & Either one: \\
\hline & 2. Asymmetric, disproportionate overgrowth & & (a) Lipomas \\
\hline & One or more: & & (b) Regional lipohypoplasia \\
\hline & (a) Limbs & & 2. Vascular malformations \\
\hline & (b) Hyperostosis of the skull & & One or more: \\
\hline & $\begin{array}{l}\text { (c) Hyperostosis of the extemal auditory } \\
\text { canal }\end{array}$ & & (a) Capillary malformation \\
\hline & (d) Megaspondyledysplasia & & (b) Venous malformation \\
\hline & (e) Viscera: & & (c) Lymphatic malformation \\
\hline & Spleen/thymus & & 3. Lung cysts \\
\hline & 3. Specific tumors before 2 nd decade & & 4. Facial phenotype \\
\hline & One of the following: & & All: \\
\hline & (a) Bilateral ovarian cystadenoma & & (a) Dolichocephaly \\
\hline & (b) Parotid monomorphic adenoma & & (b) Long face \\
\hline & & & $\begin{array}{l}\text { (c) Down slanting palpebral fissures and/orminor } \\
\text { ptosis }\end{array}$ \\
\hline & & & (d) Low nasalbridge \\
\hline & & & (e) Wide or anteverted nares \\
\hline & & & (f) Open mouth at rest \\
\hline
\end{tabular}


There is no specific treatment for Proteus syndrome. The condition should be managed by early identification of any serious medical problems and providing prophylactic and symptomatic treatment. Management of skin abnormalities may include removal of cutaneous vascular lesions using laser and surgical excision of lesions if they interfere with functional activities or for cosmetic purpose.

This case is reported for its rare presentation of segmental overgrowth of left upper limb along with both epidermal and connective tissue nevi on the same side.

\section{REFERENCES:}

1. Cohen MM Jr, Hayden PW. A newly recognized hamartomatous syndrome. Birth Defects Orig Artic Ser. 1979; 15 (5B): 291-6. [Medline].

2. Wiedemann HR, Burgio GR, Aldenhoff P, Kunze J, Kaufmann HJ, Schirg E. The proteus syndrome. Partial gigantism of the hands and/or feet, nevi, hemihypertrophy, subcutaneous tumors, macrocephaly or other skull anomalies and possible accelerated growth and visceral affections. Eur J Pediatr. Mar 1983; 140 (1): 5-12.

3. Lindhurst MJ, Sapp JC, Teer JK, et al. A mosaic activating mutation in AKT1 associated with the Proteus syndrome. N Engl J Med. Aug 18 2011; 365 (7): 611-9.

4. Turner JT, Cohen MM Jr, Biesecker LG. Reassessment of the Proteus syndrome literature: application of diagnostic criteria to published cases. Am J Med Genet A. Oct 1 2004; 130 (2): 111-22.

5. Nazzaro V, Cambiaghi S, Montagnani A, Brusasco A, Cerri A, Caputo R. Proteus syndrome. Ultrastructural study of linear verrucous and depigmented nevi. J Am Acad Dermatol. Aug 1991; 25 (2 Pt 2):377-83.

6. Biesecker LG, Happle R, Mulliken JB, Weksberg R, Graham JM Jr, Viljoen DL, et al. Proteus syndrome: diagnostic criteria, differential diagnosis, and patient evaluation. Am J Med Genet. Jun 1999; 84 (5): 389-95.

\section{PROTEUS SYNDROME - SEGMENTAL OVERGROWTH WITH MULTIPLE NEVI}

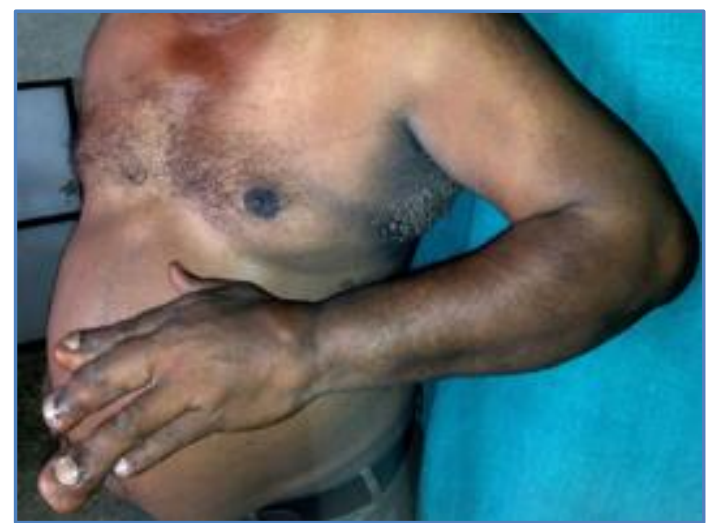

Fig. 1: Hypertrophy of left forearm with digital overgrowth

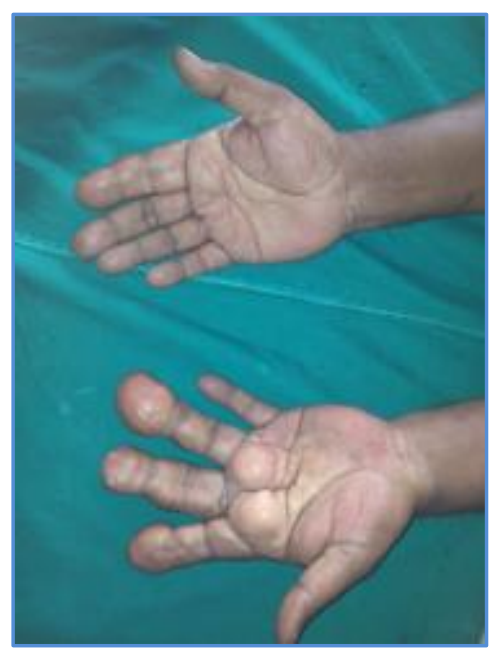

Fig. 2: Firm swellings over Left palm and digital overgrowth seen in both hands 


\section{CASE REPORT}

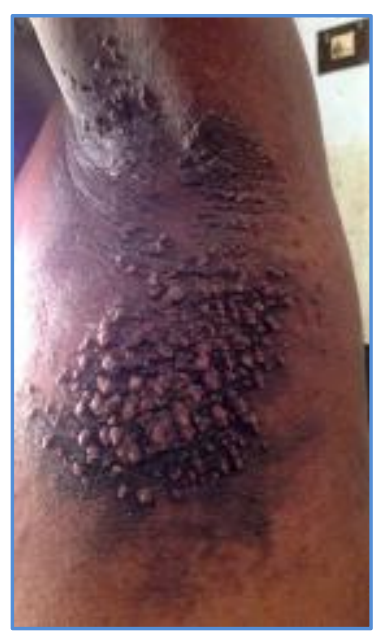

Fig. 3: Verrucous papules and plaques over left axilla-Epidermal Nevi

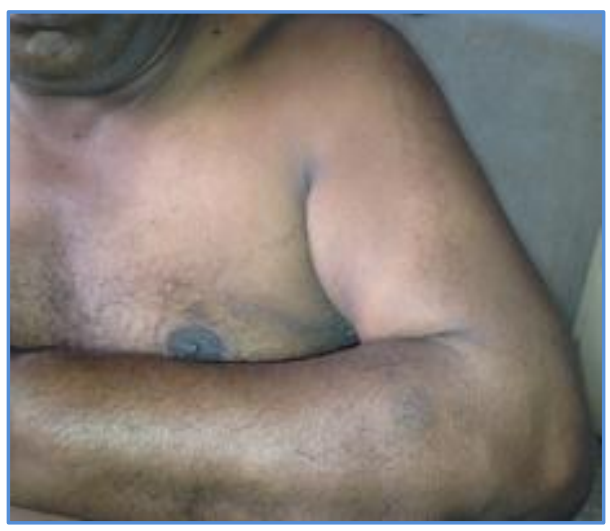

Fig. 4: Linear hyperpigmented lesion following Blaschko lines - Left shoulder and arm

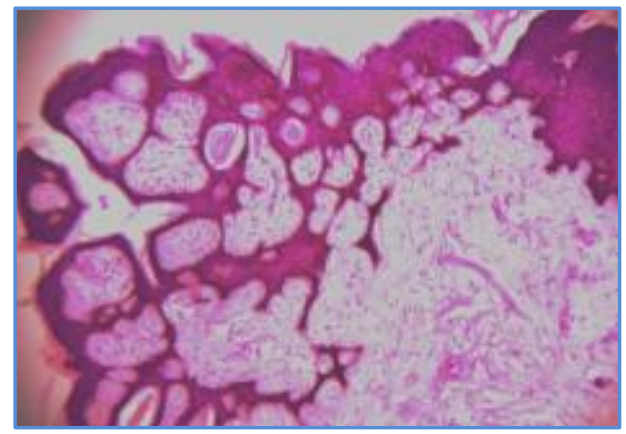

Fig. 5: H \& E staining showing epidermal hyperkeratosis, acanthosis, papillomatosis - Epidermal nevi

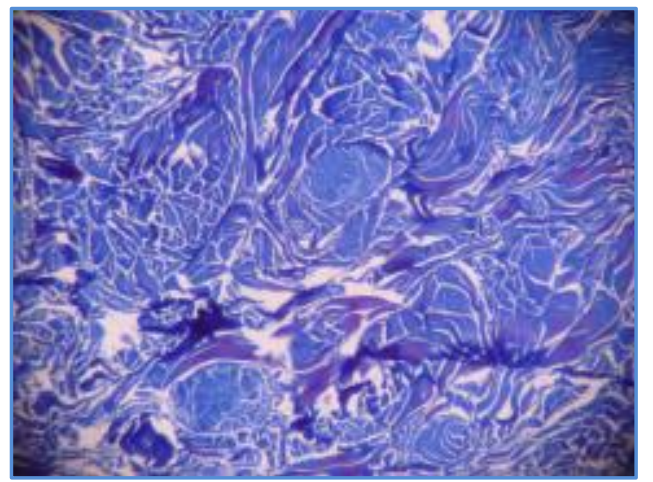

Fig. 7: Masson Trichome stain showing hypercollagen - Connective tissue nevi

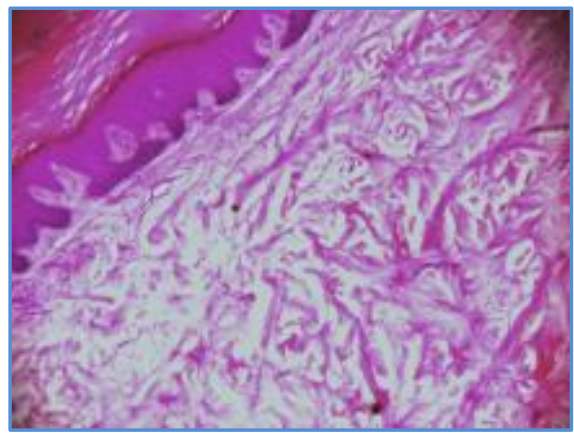

Fig. 6: H \& E staining showing increased and thickened collagen

bundles - Connective tissue nevi

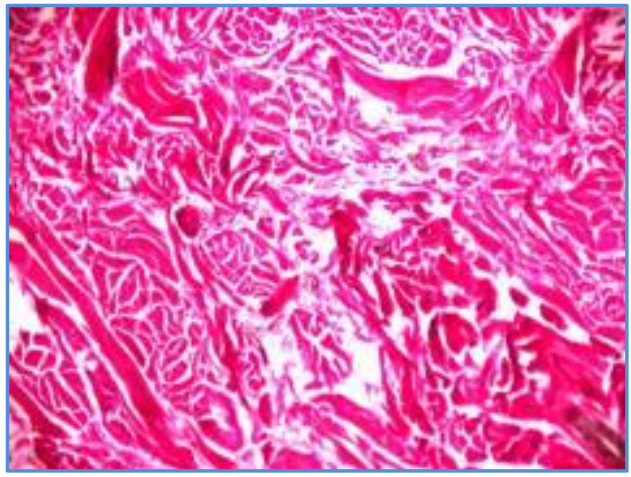

Fig. 8: Verhoeff - van Gieson stain showing hypercollagen - Connective tissue nevi 


\section{CASE REPORT}

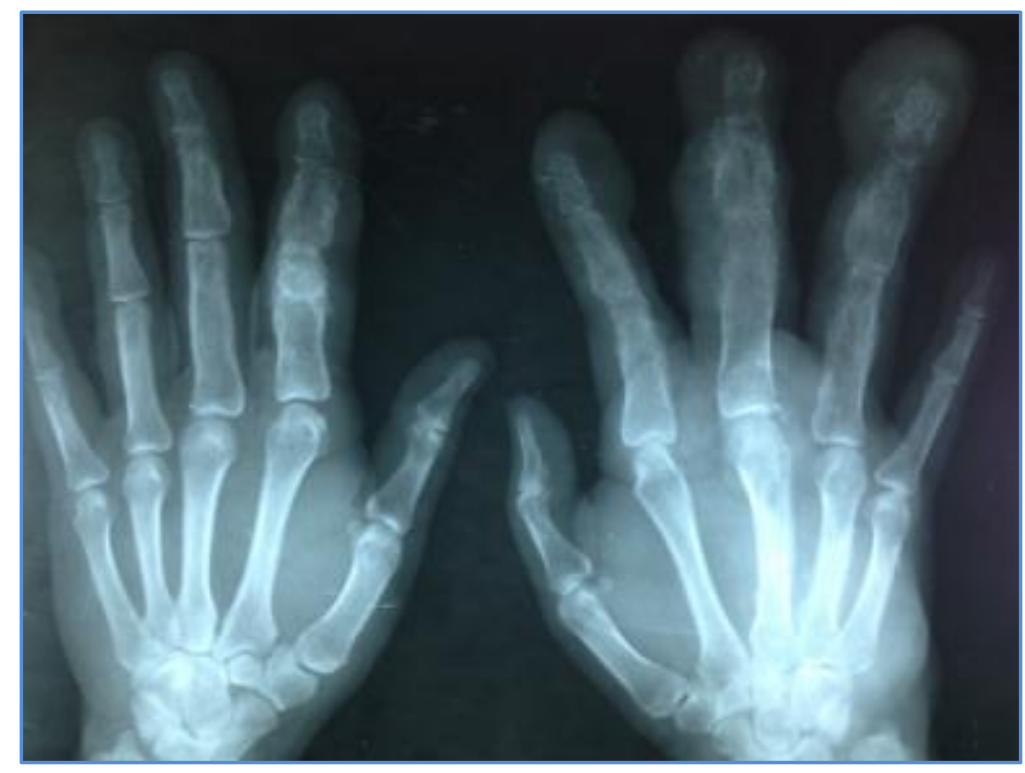

Fig. 9: X-ray of both hands showing Asymmetric macrodactyly, hyperostosis \& soft tissue overgrowth

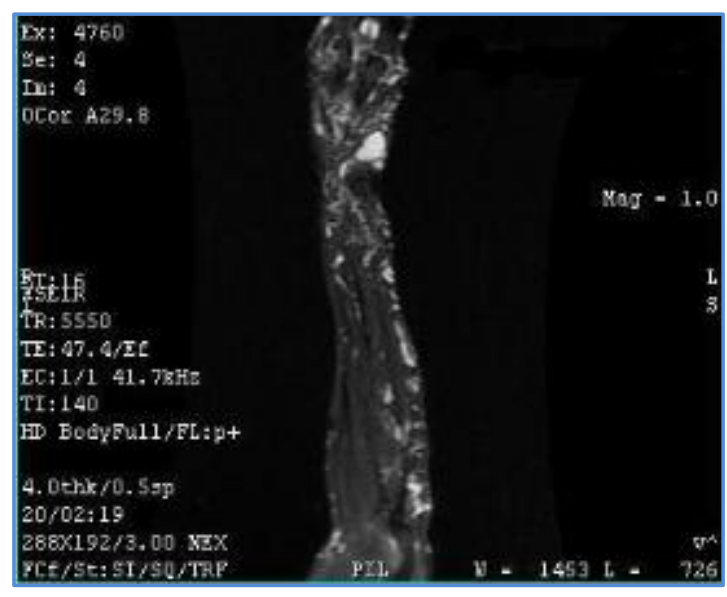

Fig. 10: CT angiogram of left upper limb showing low flow vascular malformation

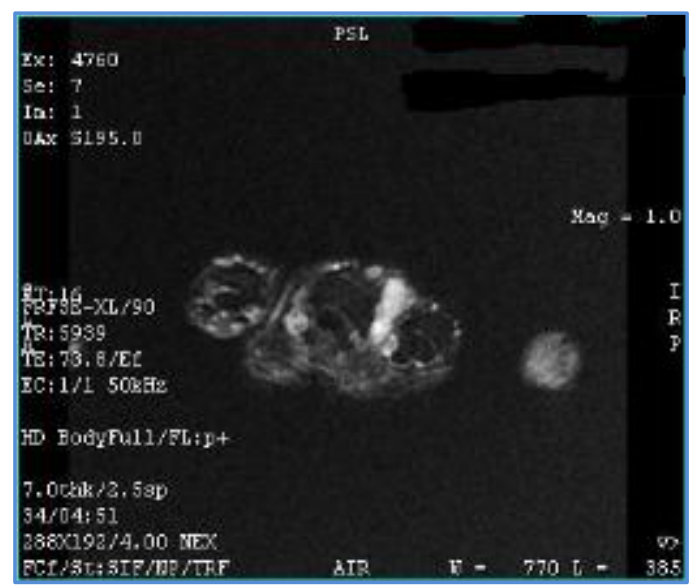

Fig. 11: CT angiogram of left upper limb showing Mild arterial prominence in ulnar, radial \& interosseous arteries 


\section{AUTHORS:}

1. P. P. Ramasamy

2. S. Bharathi

3. B. Eswaramoorthi

4. R. Madhavan

5. A. N. M. Maalik Babu

\section{PARTICULARS OF CONTRIBUTORS:}

1. Professor, Department of Dermatology, Venereology and Leprosy, Coimbatore Medical College \& Hospital, Coimbatore.

2. Assistant Professor, Department of Dermatology, Venereology and Leprosy, Coimbatore Medical College \& Hospital, Coimbatore.

3. Assistant Professor, Department of Dermatology, Venereology and Leprosy, Coimbatore Medical College \& Hospital, Coimbatore.
4. Assistant Professor, Department of Dermatology, Venereology and Leprosy, Coimbatore Medical College \& Hospital, Coimbatore.

5. Post Graduate, Department of Dermatology, Venereology and Leprosy, Coimbatore Medical College \& Hospital, Coimbatore.

\section{NAME ADDRESS EMAIL ID OF THE CORRESPONDING AUTHOR:}

Dr. P. P. Ramasamy, HOD \& Professor, Department of Dermatology, Coimbatore Medical College \& Hospital, Coimbatore-641018.

E-mail: ramasamypp@yahoo.com

Date of Submission: 02/01/2015. Date of Peer Review: 03/01/2015. Date of Acceptance: 16/01/2015. Date of Publishing: 24/01/2015. 